Pontifícia Universidade Católica DO RIO DE JANEIRO

Carla Cristina de Souza Dimarães

\begin{abstract}
Atendimento emergencial dos residentes na Fazenda da Esperança: uma experiência de retorno à vida
\end{abstract}

Dissertação de Mestrado

Dissertação apresentada ao Programa de Pós Graduação em Serviço Social da PUC-Rio como requisito parcial para obtenção do título de Mestre em Serviço Social.

Orientadora: Profa. Ilda Lopes Rodrigues da Silva 
Pontifícia Universidade Católica DO RIO DE JANEIRO

Carla Cristina de Souza Dimarães

\section{Atendimento emergencial dos residentes na Fazenda da Esperança: uma experiência de retorno à vida}

Dissertação apresentada como requisito parcial para obtenção do grau de Mestre pelo Programa de PósGraduação em Serviço Social do Departamento de Serviço Social do Centro de Ciências Sociais da PUCRio. Aprovada pela Comissão Examinadora abaixo assinada.

Profa. Ilda Lopes Rodrigues da Silva

Orientador

Departamento de Serviço Social - PUC-Rio

Profa. Andréia Clapp Salvador

Departamento de Serviço Social - PUC-Rio

Profa. Nivia Valença Barros

UFF

Profa. Mônica Herz

Vice-Decana de Pós-Graduação do Centro de Ciências Sociais - PUCC-Rio

Rio de Janeiro, 28 de julho de 2011 
Todos os direitos autorais reservados. É proibida a reprodução total ou parcial do trabalho sem autorização da universidade, da autora e da orientadora.

\section{Carla Cristina de Souza Dimarães}

Graduou-se em Psicologia na UFAM (Universidade Federal do Amazonas) em 2004. Especializou-se em Psicologia Clínica na UFAM (Universidade Federal do Amazonas) em 2006. Psicóloga Clínica, na abordagem Fenomenológicoexistencial, atua em atendimentos emergenciais e em processos psicoterápicos. Coordenadora do Serviço de Plantão Psicológico na Fazenda da Esperança, na cidade de Manaus, desde 2005. Participou de diversos congressos na área de Psicologia. Atua como Educadora no Ensino Superior no Centro Universitário do Norte UNINORTE/LAUREATE. Supervisiona e orienta alunos em Estágio curricular, nas práticas de Psicologia Clínica e Comunitária.

Ficha Catalográfica

Dimarães, Carla Cristina de Souza

Atendimento emergencial dos residentes na Fazenda da Esperança: uma experiência de retorno à vida / Carla Cristina de Souza Dimarães; orientadora: Ilda Lopes Rodrigues da Silva. - 2011. 119 f.: il. (color.); $30 \mathrm{~cm}$

Dissertação (mestrado)-Pontifícia Universidade Católica do Rio de Janeiro, Departamento de Serviço Social, 2011

Inclui bibliografia.

1. Serviço social - Teses. 2. Atendimento emergencial. 3. Plantão psicológico. 4. Uso abusivo de álcool e outras drogas. 5. Fazenda da Esperança. 6. Relação dialógica. I. Silva, Ilda Lopes Rodrigues. II. Pontifícia Universidade Católica do Rio de Janeiro. Departamento de Serviço Social. III. Título. 


\section{Agradecimentos}

A Deus, pelo dom da vida e pela possibilidade de construir-me a cada momento.

Aos meus pais, Deolinda de Souza (in memorian) e Anancir Dimarães que me ensinaram a ver a essência e não a aparência; deram-me senso de justiça e de retidão; deram-me muito amor, e a alegria profunda de me sentir querida e aceita, com falhas e acertos; ensinaram-me a enxergar minha própria beleza e acreditar no meu potencial; ensinaram-me ainda que ser ética é mais que uma obrigação; para eles e em honra deles, procuro ser sempre o melhor que puder.

À minha filha, Maria Clara, minha inspiração, força e fonte de amor. E que nos momentos de isolamento trouxe-me alegria, amor e ânimo para lutar. Dando-me muita força, nos momentos que a deixava com lágrimas nos olhos para estudar, seu sorriso sempre acalentava minha alma e me fazia prosseguir.

Ao meu esposo Jorge Hugen, que com suaves acenos tornou-se meu companheiro em momentos singulares e acreditou que era possível a concretização desse sonho. Cuidou com muito amor, de nossa filha nos momentos em que foi necessário estar ausente. E me fez saltar sobre pontes intransponíveis. Por compreender minhas ausências e acreditar que chegaria ao fim.

À minha irmã, Rafaela Reis, que me consolou e esteve ao meu lado quando parecia difícil chegar. Apoiando-me no cuidado com Maria Clara para que eu pudesse estudar.

Aos familiares, que sempre me apoiaram nos momentos difíceis e acreditaram sempre em meu potencial, estimulando-me e torcendo pela concretização dos meus sonhos.

Às amigas Jaqueline Marques e Ana Rosa Cecílio que, mesmo diante de suas dificuldades, não se esqueceram de estender a mão quando precisei de apoio, solidariedade e consolo.

Aos amigos Nazaré e Ivon, meus irmãos e companheiros, que mesmo de longe, não se esquecem de ser solidários, afetuosos, cúmplices, oferecendo amor à minha 
pessoa, nos momentos de isolamento. Com suas maneiras simples de existir, me servem de inspiração na realização dessa etapa.

Aos amigos que, com palavras de consolo, de ânimo, sempre me estimularam e acreditaram que eu iria conseguir, fazendo-me acreditar nisso quando quis desistir.

Às amigas incansáveis de Mestrado, pela vivência de momentos ímpares que estão vivos no livro de nossas vidas, e que hoje são estímulos para a concretização desse desejo.

À amiga Annie Brito, que mesmo tão distante encorajou-me, e todos os dias me estimulava com seu jeito amável de ser.

Aos amigos virtuais, que acolheram minhas angústias quando procurava incansavelmente os artigos na internet para responder a contendo as solicitações de minha orientadora.

À professora Ilda Lopes, minha estimada e querida orientadora, que com sua maneira de existir possibilitou um encontro dialógico entre o desejo de realizar um sonho e o desejo de desistir desse, fazendo-me caminhar passo a passo rumo aos ideais, compreendendo-me em minhas dificuldades e limitações. Seus gestos simples, suas palavras, considerações sábias e carinhosas cheias de encorajamento ajudou-me a concretizar esse sonho.

Aos prezados professores da PUC do Rio de Janeiro, pelo entusiasmo, pela alegria, pelo compromisso e a ética com a educação, pelos ensinamentos, pela paciência, pela compreensão, pela descoberta de novos mundos e pela promoção de possibilidades de pensar o homem, em suas maneiras de existir e em suas complexidades. Obrigada também, pela compreensão e pela paciência no momento da minha gravidez, passando por enjôos, mal-estar, sonolência, o carinho e a generosidade de vocês foram primordiais para que eu conseguisse vencer aquela etapa.

À PUC-Rio, por oportunizar a especialização do conhecimento e adentrar essas matas verdes acreditando nos potenciais aqui asilados. 
Ao Padre Anderson, que sempre me estimulou e acreditou em meu potencial, que nos faz sermos grandes, mesmo quando nos sentimos tão pequenas.

À Fazenda da Esperança, por ser um espaço rico onde se é possível descobrir o verdadeiro sentido da existência, aprendendo a olhar o outro com olhar mais humano, compreendendo-o em suas dimensões, em seu sofrimento, em sua vontade e garra de existir e jamais desistir.

Aos residentes da Fazenda da Esperança, que a cada encontro nos permitem transitar em suas experiências de vida, das mais triviais às mais sacras, possibilitando outro olhar sobre a vida. Obrigada por acreditarem em nosso trabalho e se permitirem ao novo em todos os momentos.

Aos funcionários da Fazenda da Esperança, registro aqui Cláudia Lúcia e Péricles Miranda, que contribuíram com o meu aprendizado fornecendo subsídios para que a pesquisa se concretizasse.

Ao Plantão Psicológico por permitir que se adentrasse nesse espaço de construção e de reconstrução, de encontros e desencontros. Desvelando-se e revelando-se na sua essência, sua experiência singular e transformadora.

Aos alunos do Plantão Psicológico, que sempre nos ensinam muito, com suas maneiras de existir, creditando em nós confiança, estimulando-nos durante esse processo, e ajudando-nos a compreender essa complexidade vivenciada. Obrigada por compreenderem algumas ausências e estimularem sempre a concretização dessa pesquisa.

Ao Uninorte-Laureate a oportunidade de aprimorar-me enquanto profissional, diminuindo os abismos que se colocaram na concretização desse sonho.

À professora Izolda Barreto, pelo convite e pelo estímulo para o engajamento no programa de Mestrado, a fim de qualificar-me e aprimorar meus conhecimentos.

À coordenação do curso de Psicologia, que sempre acreditou em meu potencial, dando-me oportunidades de desenvolver-me como pessoa e como profissional, ensinando-me a ser sempre ética, e comprometida com meus ideais.

Aos colegas de trabalho que com palavras de apoio estendiam sua solidariedade. 
Ao Cláudio Ladys, por ter sempre me incentivado com palavras sábias e seu jeito simples de existir.

À Joanne Oliveira e Sílvia Araújo, por ajudar-me com seus conhecimentos e estarem disponíveis quando necessitei.

Aos alunos do Uninorte-Laureate que sempre me incentivaram e compreenderamme nos momentos de ausência e de cansaço. Registro sinceros agradecimentos aos alunos da PST01S1 e PSN02S1.

À Alcimar, responsável pela biblioteca do UNINORTE, que possibilitou o empréstimo de muitos livros para que pudesse adentrar esse conhecimento vasto e rico para que se concretizasse esse sonho.

Aos funcionários da Biblioteca, que sempre gentilmente ajudavam-me na procura de livros, e muitas vezes ofereciam seus sorrisos e seus gestos amigos pela manhã quando o cansaço e a desesperança batiam a porta.

À Ouvidoria Geral do Estado, na pessoa do Deputado Francisco Souza que me dispensou de minhas atividades para freqüentar as aulas acreditando que me tornaria uma melhor profissional com os conhecimentos adquiridos.

À gravidez de Maria Clara, que me trouxe uma reflexão e um novo sentido de existir, fazendo-me ter o desejo cada vez mais forte de aperfeiçoar-me e especializar-me enquanto pessoa e profissional.

À vida, por impor suas dificuldades para que possamos descobrir com a luta o que há de melhor em nós.

A todos os gestos de carinho, atenção, solicitude, gentileza, compreensão, generosidade, apoio, encorajamento: o meu Muito Obrigada! 


\section{Resumo}

Dimarães, Carla Cristina de Souza; Silva, Ilda Lopes Rodrigues da. Atendimento emergencial dos residentes na Fazenda da Esperança: uma experiência de retorno à vida. Rio de Janeiro, 2011. 119p. Dissertação de Mestrado. Departamento de Serviço Social. Pontifícia Universidade Católica do Rio de Janeiro.

A pesquisa se delineia no espaço da Fazenda da Esperança, no Centro Masculino, situada na cidade de Manaus, que visa cuidar de dependentes de substâncias psicoativas em formato de comunidade terapêutica. $\mathrm{O}$ atendimento emergencial é desenvolvido pelo serviço do Plantão Psicológico no contexto do uso abusivo de álcool e/ou drogas e se dispõe proporcionar aqueles que estão em recuperação, o resgate de sua história, de sua existência, para devolver a possibilidade de reconstrução e de aprendizagem ao lidarem consigo mesmo e com os outros à sua volta. O estudo foi elaborado a partir da documentação do referido Plantão Psicológico, uma vez que todos os atendimentos são registrados, em fichas de atendimento. A análise desse material foi feita segundo a perspectiva compreensiva proposta por Amedeo Giorgi, para a apreensão e interpretação da experiência vivida numa relação dialógica, pelos residentes, nos atendimentos emergenciais. A partir disso, traçou-se um perfil do residente da Fazenda da Esperança relativo ao ano de 2009 e desse universo elegeu-se um caso para estudo. Desta maneira, observou-se que há possibilidades para recuperação do residente, desde que haja disponibilidade por parte dele de participar da relação dialógica que se estabelece. A experiência oferece subsídios para o retorno à sociedade, à família e ao trabalho, devolvendo-lhes os direitos dos quais fora excluído com o uso indevido de drogas e /ou álcool, resgatando sua cidadania e abrindo horizontes para a construção de um novo projeto de vida.

\section{Palavras-chave}

Atendimento emergencial; Plantão Psicológico; Uso abusivo de álcool e outras drogas; Fazenda da Esperança; Relação Dialógica. 


\section{Abstract}

Dimarães, Carla Cristina de Souza; Silva, Ilda Lopes Rodrigues da. Emergency service of residents at Fazenda da Esperança: a return to life experience. Rio de Janeiro, 2011. 119p. Dissertation. Department of Social Services. Pontifícia Universidade Católica do Rio de Janeiro.

The research is outlined within the "Fazenda Esperança", in the male center located in Manaus, aimed at caring for substance-dependent individuals in the form of therapeutic community. The emergency service is developed by psycologists on duty service in the context of alcohol abuse and / or drugs and is willing to provide those in recovery, the recovery of its history, its existence, to return the possibility of rebuilding and learning in dealing with yourself and others around you. The study was drawn from the documentation referred to psycologists on duty, since all calls are recorded in medical records. The analysis of this material was made according to the comprehensive approach proposed by Amedeo Giorgi, for the apprehension and interpretation of experience in a dialogic relationship, by residents in emergency care. From this, drew up a profile of Fazenda Esperança resident for the year 2009 and that the universe was elected a case study. Thus, it was observed that there are possibilities for recovery of the resident, subject to availability on his part to participate in the dialogic relationship that is established. The experience provides grants to return to society, family and work, giving them rights which had been excluded with the misuse of drugs and /or alcohol, recovering their citizenship and opening horizons for the construction of a new life project.

\section{Key-words}

Emergency care; Psycologists on Duty; Abuse of alcohol and other drugs; Fazenda da Esperança, Dialogical relationship. 


\section{Sumário}

Introdução

1. Plantão Psicológico e a Clínica do Encontro Dialógico

1.1. Plantão Psicológico: Percurso Histórico 17

1.2. Plantão Psicológico: Clínica do Encontro Dialógico 26

2. Drogas e Família

2.1. Conceitos Básicos e Classificação Geral das

Substâncias Psicoativas

2.2. Família e Cidadania

3. Fazenda da Esperança e o Plantão Psicológico 49

3.1. Fazenda da Esperança de Manaus 49

3.2. Plantão Psicológico na Fazenda da Esperança 55

4. Uma Experiência de Retorno à Vida 64

4.1. Perfil do residente da Fazenda da Esperança 65

4.2. Estudo de caso da Fazenda da Esperança 83

5. Considerações Finais 108

6. Referências Bibliográficas 113 


\section{Lista de Gráficos}

Gráfico 1- Em relação à idade dos residentes da Fazenda da Esperança de Manaus, atendidos pelo Plantão Psicológico em 2009 66

Gráfico 2- Em relação ao Estado Civil, dos residentes da Fazenda da Esperança de Manaus, atendidos pelo Plantão Psicológico em 2009

Gráfico 3- Em relação à quantidade de filhos, dos residentes da Fazenda da Esperança de Manaus, atendidos pelo Plantão Psicológico em 2009

Gráfico 4- Em relação ao local de nascimento, dos residentes da Fazenda da Esperança de Manaus, atendidos pelo Plantão Psicológico em 2009

Gráfico 5- Em relação à escolaridade, dos residentes da Fazenda da Esperança de Manaus, atendidos pelo Plantão Psicológico em 2009

Gráfico 6- Em relação à prática religiosa, dos residentes da Fazenda da Esperança de Manaus, atendidos pelo Plantão Psicológico em 2009

Gráfico 7- Em relação à profissão dos residentes da Fazenda da Esperança de Manaus, atendidos pelo Plantão Psicológico em 2009

Gráfico 8- Em relação ao local onde habitam os residentes da Fazenda da Esperança de Manaus, atendidos pelo Plantão 
"O Plantão Psicológico é um local onde existe uma sombra para o caminhante do 'deserto da vida', para que ele possa se recuperar, encontrar abrigo e continuar sua viagem".

Henriette Morato

São horas solenes porque nos tornam a todos mais humanos e este mesmo ritual que ao ser reencenado perpetua valores e crenças, paradoxalmente tem o dom de transformá-los. E desta mesma sociedade exaurida por inúmeros conflitos, sacudida por atos violentos, por vezes tão injusta com as minorias e tão complacente com os tiranos, surgem ainda ideais, sonhos de um mundo mais livre e de uma psicologia mais justa. 